科 学 通 报

\title{
黄骅坳陷港西断裂带无机成因 $\mathrm{CO}_{2}$ 气 的构造地球化学特征 ${ }^{*}$
}

\author{
戴春森 $^{* *}$ \\ 戴金星 \\ 杨池银王吉 韩品龙 \\ (大港石油管理局地质研究院, 天津 300280)
}

(南京大学地球科学系, 南京 210008) (石油勘探开发科学研究院, 北京 100083)

\section{关键词无机成因气、碳和氞同位事、构造地球化学}

深源或无机成因 $\mathrm{CO}_{2}$ 包括幔源 - 岩浆成因和碳酸盐岩变质热分解成因. 贯通性深断裂是 幔源 - 岩浆气上升通道, 扭压断裂带的构造热效应则为碳酸盐岩释出 $\mathrm{CO}_{2}$ 提供了热条件; 同 时, $\mathrm{CO}_{2}$ 气聚集形成的局部高孔隙压力降低了岩石的内摩擦系数, 从而激发或增强构造活动. 全球范围内深源 $\mathrm{CO}_{2}$ 释放带与世界主要地震带相一致是两者间存在内在联系的最好证明 ${ }^{[1]}$. 港西断裂带展示了不同成因 $\mathrm{CO}_{2}$ 及幔源 $\mathrm{He}$ 人侵与构造活动性的相关关系.

\section{1 地 质 背 景}

黄骅坳陷是渤海湾中, 新生代伸展构造区的次级构造单元, 坳陷区莫霍面隆起幅度达 3-4km, 最高点埋深 $30 \mathrm{~km}^{[2]}$. 港西断裂带 $\left(\mathrm{F}_{1}\right)$ 位于黄骅坳陷中部 (图 1), 下盘为持续隆起的 古生界碳酸盐岩潜山, 沿 $F_{1}$ 中生代中基性火山岩发育, 最大累计厚度超过 $500 \mathrm{~m} . \mathrm{F}_{1}$ 新生代伸 展活动强, 最大伸展断距 $2300 \mathrm{~m}$, 港 151 至沙井子段断距大, 向深部贯通性、开启性好, 两端断 距变小 ${ }^{[2]}$. 北西向徐庄子断裂 $\left(F_{2}\right)$, 为不同磁场区分界, 沿断裂带重力、磁异常带右旋水平错 断, 断裂切割深度大, 中新生代岩浆岩发育, 新生代以走滑运动为主, 研究区中生界为陆相碎 屏岩夹火山岩, 新生界为砂岩、泥岩夹生物灰岩、白云质灰岩.

60 年代初, 于港西断裂带钻遇高含 $\mathrm{CO}_{2}$ 气, 以下第三系沙一段下部和奥陶系 $\mathrm{CO}_{2}$ 气及上 第三系油田伴生含 $\mathrm{CO}_{2}$ 气的形式产出, 仅港 151 井日产 $\mathrm{CO}_{2}$ 气 $3 \times 10^{4} \mathrm{~m}^{3}$, 具有经济价值.

\section{2 样品采集测试与 He 同位素分析结果}

气样均取自钻井, 用钢瓶及排水取气两种方法取得. 气样分析结果见表 1 .

${ }^{3} \mathrm{He} /{ }^{4} \mathrm{He}$ 值是幔源挥发份对地壳人侵的灵敏指示剂 ${ }^{[3]}$. 大洋中脊、火山弧及存在地幔柱热 点的地区, ${ }^{3} \mathrm{He} /{ }^{4} \mathrm{He}$ 值从 5 倍于空气比值 $R a\left(R a=1.4 \times 10^{-6}\right)$ 至 $30 R a$ 以上, 反映地幔中储藏 有富含原始 ${ }^{3} \mathrm{He}$ 的组分. 地壳中虽有少量

1993-07-01 收稿, 1993-11-10 收修改稿.

*国家自然科学资金资助项目.

** 现在地址: 石油勘探开发科学研究院, 北京 100083 . 


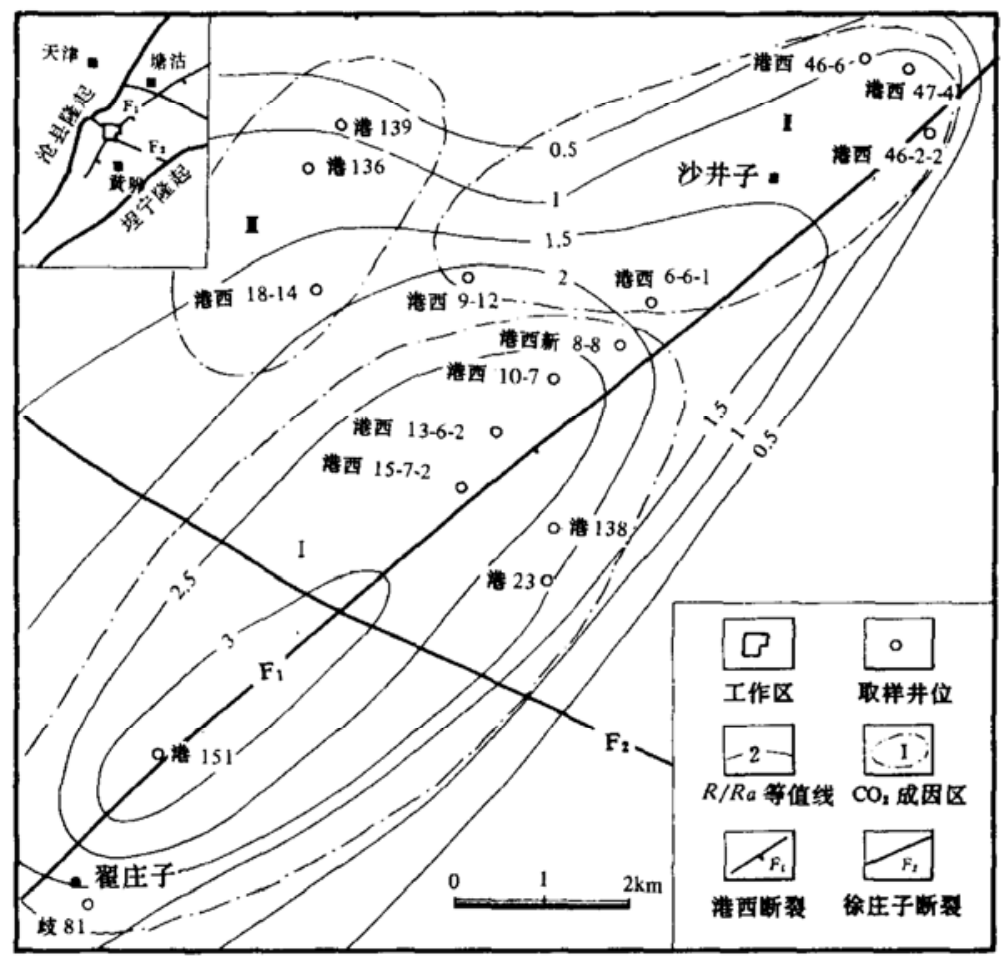

图 1 港西断裂带气样位置及 $\delta^{13} \mathrm{C}_{\mathrm{CO}_{2}}, R / R a$ 特征

I- 源 - 岩浆成因, II 一变质热分解成因, III - 有机成因

表 1 黄骓圽陷港西断裂带天然气组分及碳、氦同位索组成

\begin{tabular}{|c|c|c|c|c|c|c|c|c|c|c|c|}
\hline 位置 & 井 号 & $\begin{array}{c}\text { 井 深 } \\
\text { (m) }\end{array}$ & 层 位 & $\begin{array}{l}\mathrm{CH}_{4} \\
(\%)\end{array}$ & $\begin{array}{l}\mathrm{C}_{2}^{+} \\
(\%)\end{array}$ & $\begin{array}{l}\mathrm{CO}_{2} \\
(\%)\end{array}$ & $\begin{array}{l}\mathrm{N}_{2} \\
(\%)\end{array}$ & $\begin{array}{c}\delta^{13} \mathrm{C}_{1} \\
(\%, \text { PDB }\end{array}$ & $\begin{array}{l}\delta^{13} \mathrm{C}_{\mathrm{CO}_{2}} \\
\% 0, \mathrm{PDB})\end{array}$ & $R / R a$ & $\begin{array}{c}\mathrm{CO}_{2} \text { 主要 } \\
\text { 来源 }\end{array}$ \\
\hline \multirow{4}{*}{ 中 } & 港 151 & $1632-1639$ & $\overline{\mathrm{E}_{\mathrm{S}_{1} \mathrm{~F}}}$ & 1.17 & 0 & 98.61 & 0.19 & -28.60 & -3.77 & 3.62 & \multirow{8}{*}{$\begin{array}{c}\text { 源 - 岩 } \\
\text { 浆成因 }\end{array}$} \\
\hline & 歧 81 & $2239-2241$ & $\mathrm{E}_{\mathrm{S}_{1 \mathrm{~F}}}$ & 76.03 & 20.62 & 2.49 & 0.68 & $-54,91$ & -6.75 & 1.69 & \\
\hline & 港西新 8-8 & $1035-1198$ & $\mathbf{N}_{\mathrm{m}}$ & 71.59 & 6.07 & 21.36 & 0.98 & -45.83 & -3.51 & 2.17 & \\
\hline & 港 23 & $1774-1877$ & $E_{d}$ & 63.37 & 14.84 & 20.86 & 0.79 & -44.30 & -7.72 & 2.24 & \\
\hline \multirow{4}{*}{ 段 } & 港 138 & $1462-1467$ & $\mathbf{N}_{\mathbf{g}}$ & 66.86 & 14.07 & 18.93 & - & -43.86 & -7.10 & 2.06 & \\
\hline & 港西 $10-7$ & $1345-1406$ & $\mathrm{~N}_{8}$ & 67.12 & 9.66 & 21.88 & 1.34 & -51.03 & -7.40 & 2.72 & \\
\hline & 港西 13-6-2 & $1087-1094$ & $\mathbf{N}_{\mathrm{g}}$ & 91.98 & 3.27 & 4.72 & - & -49.55 & -8.86 & 2.74 & \\
\hline & 港西 15-7-2 & $1252-1279$ & $\mathbf{N}_{\mathrm{m}}$ & 91.01 & 2.47 & 4.85 & 1,62 & -50.68 & -11.66 & 2.80 & \\
\hline \multirow{5}{*}{ 段 } & 港西 9-12 & $899-908$ & $\mathbf{N}_{\mathrm{m}}$ & 81.23 & 0.88 & 17.42 & 0.47 & -49.98 & -0.4 & 2.04 & \multirow{5}{*}{$\begin{array}{c}\text { 变质热分 } \\
\text { 解成因 }\end{array}$} \\
\hline & 港西 46-2-2 & $1260-1282$ & $\mathbf{N}_{\mathrm{m}}$ & 83.00 & 4.33 & 10.58 & 2.06 & -42.23 & +0.07 & - & \\
\hline & 港西 6-6-1 & & $\mathbf{N}_{\mathrm{m}}$ & 83.97 & 3.89 & 11.21 & 0.86 & -44.46 & +1.58 & 1.76 & \\
\hline & 港西 46-6 & $977-1225$ & $\mathbf{N}_{m}$ & 70.62 & 9.12 & 20.33 & - & -31.19 & - & 1.06 & \\
\hline & 港西 47-4 & $1036-1120$ & $\mathbf{N}_{\mathrm{m}}$ & 82.27 & 5.25 & 11.22 & 1.25 & -43.34 & +1.72 & 0.96 & \\
\hline \multirow{3}{*}{ 岩 } & 港西 18-14 & $1021-1042$ & $\mathbf{N}_{\mathrm{m}}$ & 96.22 & 2.06 & 0.51 & 1.19 & -52.57 & -14.01 & 1.89 & \multirow{3}{*}{ 有机成因 } \\
\hline & 港 136 & $1254-1255$ & $\mathbf{N}_{\mathrm{m}}$ & 98.37 & 0.22 & 0.28 & 1.12 & -57.99 & -18.67 & 1.19 & \\
\hline & 港 139 & & $\mathbf{N}_{\mathbf{g}}$ & 97.58 & 0.24 & 0.26 & 1.91 & -58.94 & -20.37 & 0.96 & \\
\hline
\end{tabular}

$$
{ }^{6} \mathrm{Li}(n, \alpha) \stackrel{\beta}{\longrightarrow}{ }^{3} \mathrm{He}
$$

反应生成的 ${ }^{3} \mathrm{He}$, 但仍以 $\mathrm{U}, \mathrm{Th}$ 的 $\alpha$ 衰变产生的 ${ }^{4} \mathrm{He}$ 为主, 故典型壳源流体的 ${ }^{3} \mathrm{He} /{ }^{4} \mathrm{He}$ 值低于 
$0.04 R a^{[4]}$

港西断裂带气样 ${ }^{3} \mathrm{He} /{ }^{4} \mathrm{He}$ 值 $0.96-3.62 R a$, 存在强烈的幔源 $\mathrm{He}$ 混染, 幔源 $\mathrm{He}$ 异常中心位 于 $\mathrm{F}_{1}$ 与 $\mathrm{F}_{2}$ 交汇带, 港 151 和港西 15-7-2 之 ${ }^{3} \mathrm{He} /{ }^{4} \mathrm{He}$ 值分别达 $3.62 R a$ 和 $2.80 R a, R / R a$ 值自交 汇带向四周降低 (图 1). 沿港西断裂自交汇带向两侧 $R / R a$ 值由港 151 的 3.62 降至港西 47-4 的 0.96 (图 2) 和歧 81 的 1.69. 自港西断裂向围岩则由港 151 的 3.62 降至港 139 的 0.96 和港 23 的 2.24 (图 3), 反映幔源 $\mathrm{He}$ 自交汇带人侵沿港西断裂运移并向围岩扩散.

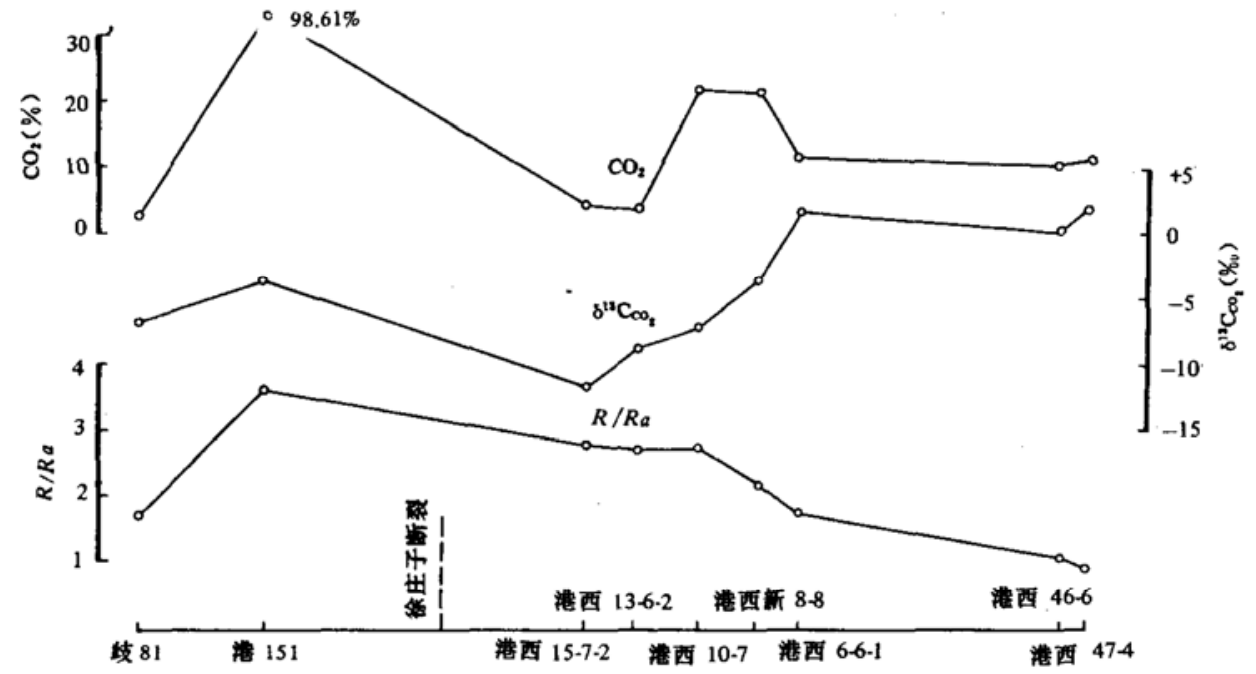

图 2 沿港西断裂带 $R / R a$ 值、 $\mathrm{CO}_{2}$ 含量及 $\delta^{13} \mathrm{C}_{\mathrm{OO}_{2}}$ 变化特征

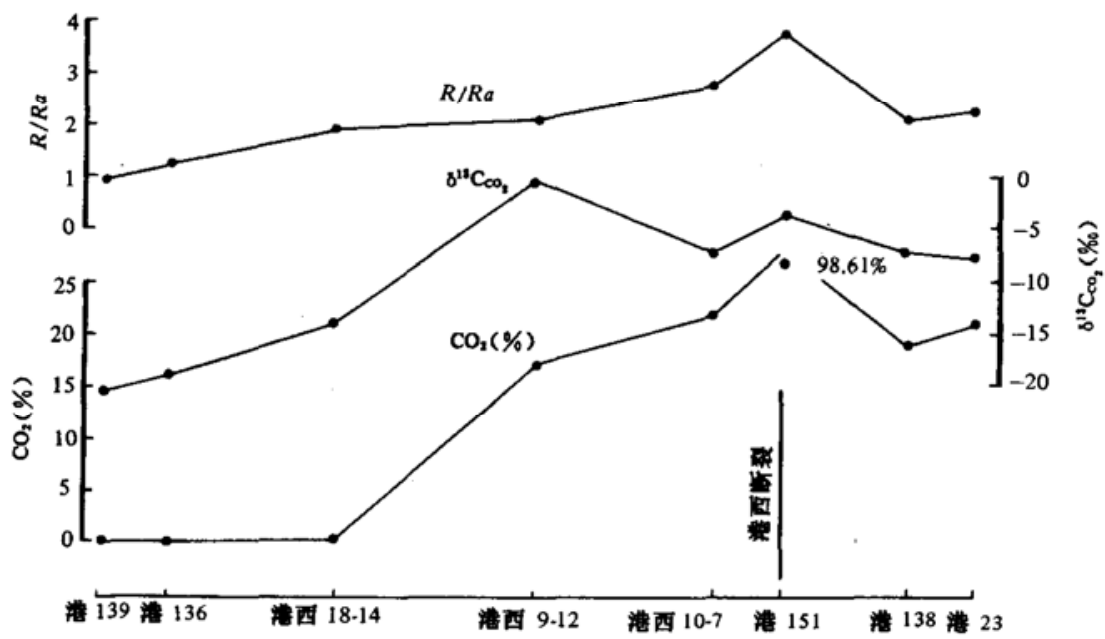

图 3 港西断裂带 $R / R a$ 值、 $\mathrm{CO}_{2}$ 含量及 $\delta^{13} \mathrm{C}_{\mathrm{CO}_{2}}$ 横剖面图

\section{3 二氧化碳碳同位素及其构造地球化学特征}

天然气中 $\mathrm{CO}_{2}$ 含量 $0.24 \%$ 至 $98.61 \%, \delta^{13} \mathrm{C}_{\mathrm{CO}_{2}}$ 值 $-20.37 \%$ 至 $+1.72 \%$ (表 1$)$, 不同构造 部位 $\mathrm{CO}_{2}$ 含量及 $\delta^{13} \mathrm{C}_{\mathrm{CO}_{2}}$ 值呈现不同特征(图 1).

$\mathrm{I}$ 区, 位于 $\mathrm{F}_{1}$ 和 $\mathrm{F}_{2}$ 交汇带, $\mathrm{CO}_{2}$ 含量 $2.47 \%$ 至 $98.61 \%, \delta^{13} \mathrm{C}_{\mathrm{CO}_{2}}$ 为 $-7.72 \% 0$ 至 $-3.51 \% 0$. 
太平洋中脊玄武岩极纯 $\mathrm{CO}_{2}$ 流体包裹体的 $8^{13} \mathrm{C}_{\mathrm{co}}$ 值为 $-8.0 \%$ 至 $-4.7 \%{ }^{19}$; 加利莫夫研究金 刚石的 $\delta^{13} \mathrm{C}$ 值, 主频率 $-7 \% 0$ 至 $-4 \%$ 被认为是幔源碳同位素的可能区间, 故 I 区 $\mathrm{CO}_{2}$ 主要是 幔源 - 岩浆成因的. 伴生 ${ }^{3} \mathrm{He} /{ }^{4} \mathrm{He}$ 值 1.69 至 $3.62 R a$, 与幔源 $\mathrm{He}$ 人侵中心重合, 说明幔源 - 岩 浆气来源充分. 港西 15-7-2、港西 13-6-2 $\mathrm{CO}_{2}$ 含量 $4.85 \%$ 和 $4.72 \%, \delta^{13} \mathrm{C}_{\mathrm{CO}_{2}}$ 值 $-11.66 \%$ 和 $-8.86 \%$ 则显示受有机成因 $\mathrm{CO}_{2}$ 影响较大.

II区, 位于 $\mathrm{F}_{1}$ 东北段, $\mathrm{CO}_{2}$ 含量 $10.58 \%$ 至 $20.33 \%, \delta^{13} \mathrm{C}_{\mathrm{CO}}-0.4 \%$ 至 $+1.72 \%$ 。碳酸盐 岩变质热分解成因 $\mathrm{CO}_{2}$ 之 $8^{13} \mathrm{C}_{\mathrm{co}_{2}}$ 值接近于 $0 \%{ }^{16}$ 或 $-2 \% 0$ 至 $+2 \%{ }^{17}$, 回区之 $\delta^{13} \mathrm{C}_{\mathrm{CO}_{2}}$ 位于这 一区间, ${ }^{3} \mathrm{He} /{ }^{4} \mathrm{He}$ 值 0.96 至 $2.04 \mathrm{Ra}$, 说明幔源 $\mathrm{He}$ 混染依然强烈, 但 $\mathrm{CO}_{2}$ 却主要为壳源变质热 分解成因. 图 2 显示 I区 受交汇带扩散幔源 $\mathrm{He}$ 的影响, 因 $\mathrm{CO}_{2}$ 的扩散系数远小于 $\mathrm{He}$, 随着 距交汇带距离增加, $\delta^{13} \mathrm{C}_{\mathrm{CO}}$ 值逐渐增高, 至 $\Pi$ 区为典型变质热分解成因, 显示两种无机成因 $\mathrm{CO}_{2}$ 端元沿港西断裂的释出与混合.

III 区, 距断裂带较远 (图 1), $\mathrm{CO}_{2}$ 含量 $0.26 \%$ 至 $2.06 \%, \delta^{13} \mathrm{C}_{\mathrm{CO}_{2}}-20.37 \%$ 至 -14.01 $\%$, 低于 Craig ${ }^{16}$ 划分的有机成因 $\delta^{13} \mathrm{C}_{\mathrm{CO}}$ 值之上限 $-12 \%$, II区 $\mathrm{CO}_{2}$ 主要是有机成因的. 自港 139 向断裂带方向 $\mathrm{CO}_{2}$ 含量及 $\delta^{13} \mathrm{C}_{\mathrm{CO}}$ 增高趋势明显 (图 3), ${ }^{3} \mathrm{He} /{ }^{4} \mathrm{He}$ 值亦由港 139 的 $0.96 R a$ 变化至港西 10-7 和港 151 的 2.72 和 3.62Ra, 表明围岩的壳源 $\mathrm{He}$ 及有机成因 $\mathrm{CO}_{2}$ 受断裂带扩 散的深源无机成因气的混染, 而幔源 $\mathrm{He}$ 的混染强度显然强于 $\mathrm{CO}_{2}$.

\section{4 讨 论}

沿港西断裂带存在两个无机成因 $\mathrm{CO}_{2}$ 端元, 即交汇带的幔源 - 岩浆成因端元和 $\mathrm{F}_{1}$ 东北段 的变质热分解成因 $\mathrm{CO}_{2}$ 端元. 钻井及地震资料表明 I 区和 I 区中生代火山岩发育特征并无 明显差异 ${ }^{[2]}$, 且经过中生代末至新生代古新世约 $45 \mathrm{Ma}$ 的剥蚀准平化化, 与中生代岩浆作用有 关的无机成因气多已散失, 故中生代岩浆活动可能是非区内无机成因气的主要来源, 不同成因 $\mathrm{CO}_{2}$ 的分布特征是由新生代构造活动特点决定的.

港西断裂带港 151 至沙井子段新生代伸展断距最大, 向深部延伸稳定, 贯通性及开启性好 ${ }^{[2]}$, 加之徐生子断裂新生代的张扭性活动, 故 I 区是幔源 - 岩浆气的有利释放部位. 港西断裂东 北段向深部产状变缓, 具铲式正断层特征, 断裂深部贯通性及开启性差 ${ }^{[2}$, 呈压性断裂的应力 特征, 不利于幔源 - 岩将气的直接排放, 故幔源 - 岩浆气的来源远不及 I 区. 但压性或压扭性断 裂具增温效应: 一种是断裂活动的机械生热 ${ }^{[8]}$; 另一种是动力学剪切生热, 地震活动时剪切热 可以在断裂面产生上千度高温 ${ }^{[9]}$, 热变质作用强, 这可能是 II 区变质热分解成因 $\mathrm{CO}_{2}$ 端元形 成的根本原因.

致谢衰心感谢导师郭令智教授、施央申教授、孙岩教授的悉心指导.

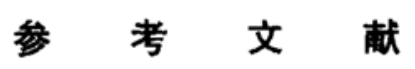

(1] Irwin, W. P., Jour. Geophys. Res., 1980, 85:3115-3121.

[2] 中国石油志编委会, 大港油田石油地质志, 石油. [业出版社, 北京, 1991.

[3] Lupton, J. E., Ann. Rev. Earth Planet, Sci., 1983, 11:371-414. 
[4] Jenden, P. D. et al., Geochim. Cosmochim. Acta, 1988, 52:851-861.

[ 5] Moore, J. G. et al., Jour. Volcanol. Geothermal Res., 1977, (2):309-327.

[6] Craig, H., Geochim. Cosmochim. Acta, 1953, (3): 53-95.

[7] Stahl, W. J. et al., AAPG, 1981, 65:1543-1550.

[8] Scholz, C. H., Jour. Geophys. Res., 1980, 85:6174-6184.

[9] Sibson, R. H., Bull. Seismol. Soc. Am., 1982, 72:151-163. 